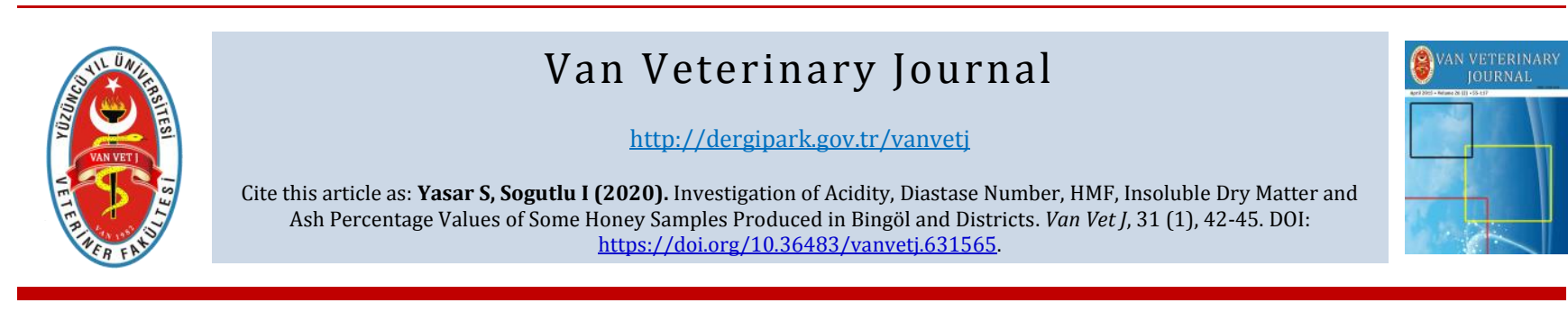

\title{
Investigation of Acidity, Diastase Number, HMF, Insoluble Dry Matter and Ash Percentage Values of Some Honey Samples Produced in Bingöl and Districts
}

\author{
Semih YAŞAR1® İnci SöĞÜTLÜ2® \\ ${ }^{1}$ Van Yuzuncu Yil University, Özalp Vocational School, Department of Medical Laboratory Technician, Van, Turkey \\ 2 Ministry of Agriculture and Forestry General Directorate of Food and Control Department of Food Enterprises and Codex, Ankara, Turkey
}

Received: 10.10 .2019

Accepted: 05.03.2020

ABSTRACT Bingöl province and its districts are very suitable for beekeeping with rich vegetation and suitable climatic conditions. Eight honey samples were collected from Bingöl province and districts and analyzed. As a result of these analyzes, the mean free acidity was 10.675 meq / kg, the number of diastases was 22.5, the HMF was $45.148 \mathrm{mg} / \mathrm{kg}$, the water-insoluble dry matter was $0.00575 \%$ and the ash percentage was $0.45 \%$. The biochemical analysis of the samples shows that the honeys examined meet the criteria of Turkish Food Codex. In order to ensure the development of beekeeping and quality honey production in the region, educational activities, controls and financial support should be increased with various projects.

Keywords: Ash percentage, Diastasis, Flower honey, HMF

ÖZ

\section{Bingöl ve İlçelerinde Üretilen Bazı Bal Örneklerinin Asitlik, Diyastaz Sayısı, HMF, Suda Çözülmeyen Kuru Madde ve Kül Yüzdesi Değerlerinin Araştırılması}

Bingöl ili ve ilçeleri zengin bitki örtüsü ve uygun iklim koşulları ile arıcılık için çok uygun bir bölgedir. Sunulan çalışmada Bingöl ve ilçelerinde üretilen bazı bal örneklerinin serbest asitlik, diyastaz sayısı, HMF, suda çözülmeyen kuru madde ve kül yüzdesi ölçülerek sonuçların standartlara uygunluğunun araştırılması amaçlandı. Bingöl ili ve ilçelerinden 8 adet bal örneği toplanarak analizleri yapıldı. Bu analizler sonucunda ortalama serbest asitlik $10.675 \mathrm{meq} / \mathrm{kg}$, diyastaz sayısı 22.5, HMF $45.148 \mathrm{mg} / \mathrm{kg}$, suda çözülmeyen kuru madde \%0,00575 ve kül yüzdesi \%0,45 olarak bulundu. Örneklerin biyokimyasal analizleri incelenen balların Türk Gıda Kodeksi kriterlerine uyduğunu göstermektedir. Bölgede arıcılı̆̆ın gelişmesini ve kaliteli bal üretimini sağlayabilmek için eğitimsel faaliyetlerin, kontrollerin ve çeşitli projelerle mali desteğin arttırılması gerekmektedir.

Anahtar Kelimeler: Çiçek balı, Diyastaz, HMF, Kül yüzdesi

\section{Gíriș}

Bal, arılar (Apis mellifera) tarafindan çiçeklerden nektarlar toplanarak leziz bir gıda ürününe dönüştürülen, şekerden daha yararlı olduğu bilinen doğal bir üründür (Vanhanen ve ark. 2011). Çoğunlukla şeker (fruktoz ve glikoz) ve enzimler, amino asitler, organik asitler, karotenoidler, vitaminler, mineraller ve aromatik maddeler gibi diğer bileşenlerden oluşan bir besindir. Çok çeşitli biyolojik etkiler gösteren flavonoidler ve fenolik asitler bakımından zengindir ve doğal antioksidanlar gibi davranır (Alqarni ve ark. 2012). Bal üretim kaynağına göre çiçek ve salgı balı olarak sınıflandırılmaktadır. Çiçek balı bitki nektarlarından elde edilir, salgı balı ise bitkilerde bulunan canlı kısımlar üstünde yaşayan bitki emici böceklerin salgılarından veya yine bitkilerdeki canlı bölümlerin salgılarından elde edilir (TGK 2012). Doğal bir gıda olan bal içerisinde sağlık için yararlı birçok biyoaktif madde bulundurur. Bal içerisine dışarıdan herhangi bir madde eklenmesi ya da balın bileşimindeki bir maddenin uzaklaştırılması yönetmelik ve kanunlar ile yasaklanmıştır (Karadal ve Yıldırım 2012). Türk Gıda Kodeksi Bal Tebliği'ne göre balda olması istenen bazı özellikleri aşağıda Tablo 1'de verilmiștir (TGK 2012).

Türkiye, bal üretimi için uygun mevsim şartları, topografik yapısı ve zengin bitki florasına sahip nadir ülkelerden biridir. Bingöl ili ise Türkiye'nin doğusunda bulunmakla birlikte coğrafi yapısı ve zengin bitki örtüsüyle Türkiye'nin en verimli ve kaliteli ballarının üretildiği bir ilimizdir. Türkiye Dünyada ballı bitki türlerinin dörtte üçüne sahip olmasına rağmen, bal üretimi ve tüketimi bakımından dünyada yerini tam olarak alamamıștır (Şişek ve ark. 2007). Yapılan bu çalışmada Bingöl ili ve ilçelerinde üretilen balların bazı kimyasal parametrelerinin standartlarla ilişkisi araştırılmaktadır. 
Tablo 1. Bal Tebliği'ne (2012/58) göre balın sahip olması gereken özellikleri (TGK 2012)

Table 1. According to the Communiqué on Honey (number: 2012/58), honey should have the characteristics (TGK 2012)

\begin{tabular}{|c|c|c|c|}
\hline $\begin{array}{l}\text { Özellik (100 } \mathrm{g} \\
\text { balda) }\end{array}$ & Çiçek balı & Salgı balı & Karışım \\
\hline Su (en fazla, g) & 20 & 20 & 20 \\
\hline $\begin{array}{l}\text { Sakkaroz } \\
\text { (en fazla, g) }\end{array}$ & $5-10$ & $5-10$ & $5-10$ \\
\hline $\begin{array}{l}\text { Fruktoz + glikoz } \\
\text { (en az, g) }\end{array}$ & 60 & 45 & 45 \\
\hline $\begin{array}{l}\text { Suda çözülmeyen } \\
\text { madde } \\
\text { (en fazla, g) }\end{array}$ & 0.1 & 0.1 & 0.1 \\
\hline $\begin{array}{l}\text { Serbest asitlik } \\
\text { (en fazla, } \\
\text { meq/kg) }\end{array}$ & 50 & 50 & 50 \\
\hline $\begin{array}{l}\text { Diastaz sayısı } \\
\text { (en az) }\end{array}$ & 8 & 8 & 8 \\
\hline $\begin{array}{l}\text { HMF } \\
\text { (en fazla, ppm) }\end{array}$ & 40 & 40 & 40 \\
\hline $\begin{array}{l}\text { Prolin miktarı } \\
\text { (en az, ppm) }\end{array}$ & 300 & 300 & 300 \\
\hline $\begin{array}{l}\text { Naftalin miktarı } \\
\text { (en fazla, ppb) }\end{array}$ & 10 & 10 & 10 \\
\hline
\end{tabular}

\section{MATERYAL ve METOT}

Bingöl, Türkiye'nin Doğu Anadolu Bölgesi'nde yer alan bir ildir. İlin yüzölçümü $8.004 \mathrm{~m}^{2}$ 'dir. İl merkezinin denizden yüksekliği 1159 m'dir. Bingöl ilinin genelinde üretilen balların asitlik, diyastaz sayısı, HMF, suda çözülmeyen kuru madde ve kül yüzdesi özelliklerini belirlemek amacıyla 2013 yılının Ağustos, Eylül, Ekim ayları içerisinde, Bingöl ve ilçelerinde bal üretimi yapan arıcılardan temin edildi. Bu çalışmada materyal olarak 8 ayrı çiçek balı kullanıldı. Bal örnekleri, ağzı kapalı kaplarda toplandı ve analiz süresi boyunca oda sıcaklığında $\left(22^{\circ} \mathrm{C}^{\prime}\right.$ de $)$ muhafaza edildi. Muhafaza esnasinda bal örneklerine herhangi bir fiziksel veya kimyasal işlem uygulanmadı.

Ballarda serbest asitlik tayini TS 13360' a göre, diyastaz sayısı tayini TS 13364'e göre, hidroksi metil furfural (HMF) muhtevası tayini TS 13356'ya göre, suda çözünmeyen kuru madde tayini TS 3036'ya, kül yüzdesi tayini TS 2131'e göre yapılmıștır.

\section{BULGULAR}

Bingöl ve ilçelerinde üretilen ballarda asitlik, diyastaz sayısı, HMF, suda çözülmeyen kuru madde ve kül yüzdesi analizleri yapıldı. Sonuçlar tablo şeklinde aşağıda verilmiştir.

Tablo 2. Bingöl ve ilçelerinde üretilen bal örneklerinin analiz sonuçları

Table 2. Analysis of honey samples produced in Bingöl and districts

\begin{tabular}{|c|c|c|c|c|c|c|}
\hline & $\begin{array}{l}\text { Asitlik } \\
\text { (meq/kg) }\end{array}$ & $\begin{array}{l}\text { Diastaz } \\
\text { Sayısı }\end{array}$ & $\begin{array}{l}\text { HMF } \\
\text { (mg/kg) }\end{array}$ & $\begin{array}{l}\text { Suda Çözülmeyen } \\
\text { Madde Miktarı (\%) }\end{array}$ & $\begin{array}{l}\text { Kül } \\
(\%)\end{array}$ & Yüzdesi \\
\hline Bingöl-Karlıva & 25 & 17.9 & 35.315 & 0.007 & 0.42 & \\
\hline Bingöl-Solhan & 20 & 8.3 & 23.595 & 0.009 & 0.54 & \\
\hline Bingöl-Genç & 21 & 10.9 & 36.335 & 0.008 & 0.39 & \\
\hline Bingöl-Merkez & 25 & 23 & 34.725 & 0.001 & 0.43 & \\
\hline Bingöl-Sancak Beldesi & 22.5 & 1 & 28.98 & 0.011 & 0.51 & \\
\hline Bingöl-Yedisu & 23 & 10.9 & 28.92 & 0.002 & 0.47 & \\
\hline Bingöl-Çaytepe köyü & 21.5 & 2.5 & 42.22 & 0.001 & 0.45 & \\
\hline Bingöl-Yayladere & 22 & 10.9 & 27.01 & 0.007 & 0.41 & \\
\hline Ortalama Değer & 10.675 & 22.5 & 45.148 & 0.00575 & 0.45 & \\
\hline
\end{tabular}

\section{TARTIŞMA ve SONUÇ}

Bal arılar tarafından üretilen doğal bir gıda olup, diğer arıcılık ürünleri olan propolis, arısütü, arı zehri, balmumu, polen gibi diğer arı ürünlerine göre temin edilebilirliği ve tüketimi daha yüksektir (Karadal ve Yıldırım 2012). Bu özelliği sebebiyle üzerinde en kolay oynanan gidalardan biridir. Saf bal hiçbir katkı maddesi olmadan arıların çiçek nektarlarından ürettiği gıdadır. Ancak verimi arttırmak için çeşitli şeker şurupları kullanılarak da bal üretimi yapılmaktadır (Paradkar ve Irudayaraj 2001).

Balın asitliğini içeriğinde bulunan mineral maddeler ve organik asitler, karbonhidratlar ve aminoasitlerdir (Ötleş 1995). Asitlik, balın bitkisel kaynağına ve üretim yapılan bölgeye bağlı olarak farklılık gösterebilmektedir. Serbest asitlik balın depolanma süresi ve nem içeriğine bağlı olarak biraz artmakta, ancak depolama sıcaklığı ile değişim göstermemektedir (Terrab ve ark. 2004). Doğu ve Güneydoğu Anadolu bölgelerinden toplanan bal örneklerinde yapılan bir çalışmada ortalama serbest asitlik değeri $22.3 \mathrm{meq} / \mathrm{kg}$ tesbit edilmiştir (Yllmaz ve Küfrevioğlu 2001). Batu ve arkadaşları (2013) yaptıkları çalışmada toplam asitlik değerlerini $6.73-47.06 \mathrm{meq} / \mathrm{kg}$ arasında ve ortalamasını da $32.49 \mathrm{meq} / \mathrm{kg}$ olarak belirlemişlerdir. Ülkemizde ayçiçek ballarında yapılan başka bir araștırmada toplam asitlik miktarı ortalama 14.35 meq/kg olarak ölçülmüştür (Velioğlu ve Köse 1983). Gaziantep bölgesinde üretilen çiçek ballarda yapılan başka bir çalışmada ise asitlik değerlerinin ortalama 26.1106 meq/kg olduğu görülmüștür (Kutlu ve Bengü 2015).

Çalışmamızda toplam asitlik bakımından en düşük değer $20 \mathrm{meq} / \mathrm{kg}$ ile Bingöl-Solhan, en yüksek değer ise 25 meq/kg ile Bingöl-Karlıova örneklerinden elde edilmiştir. Tüm örneklerin ortalaması $22.5 \mathrm{meq} / \mathrm{kg}$ olarak bulunmuștur. Türk Gıda Kodeksi Yönetmenliğine göre, 
baldaki toplam asitlik değeri $50 \mathrm{meq} / \mathrm{kg}^{\prime} \mathbf{~ a s ̦ m a m a l ı d ı r . ~}$ Çalışmamızdaki çiçek ballarının ölçülen asitlik değerlerinin Türk Gıda Kodeksi Bal Tebliği'ne uygun olduğu tespit edilmiştir.

Diastaz sayısı $40{ }^{\circ} \mathrm{C}^{\prime}$ de 1 saatte 1 gram balın parçaladığı nişastanın gram olarak değeridir (Şahinler ve ark. 2001). Türk Gıda Kodeksi Bal Tebliği'ne (2012/58) göre diastaz sayısı ballarda en az 8 olmalıdır. Balın olgunlaștırılması sırasında, bal arıları diyastaz enzimini salgılarlar, bu enzim ısı etkisi ile kolay alarak parçalanabilmektedir. Isıya maruz kalan balların diyastaz sayıları hızla azalır, diyastaz sayısı yüksek olan ballarda ise fazla asit oluşumuna bağlı daha çabuk mayalanma oluşmaktadır (Tolon 1999). Balın üretildiği bitkilerin kaynağına ve bölgenin florasına bağlı olarak balda değişik düzeylerde bulunurken, diyastaz sayısının tahmin edilen miktardan az ya da çok tespit edilmesi balın kalitesinin belirlenmesinde yardımcı olabilmektedir (Artık 2004).

Batu ve arkadaşlarının (2013) yaptıkları analiz sonuçlarına göre bal örneklerinin diyastaz sayılarının 8.317.9 arasında değiştiğini ve ortalama ise yaklaşı 13.9 olarak gerçekleștiğini bildirmişlerdir. Yapılan bir çalışmada çiçek ve salgı ballarının diyastaz sayılarını sirasıyla 22.68 ve 25.29 olarak bulmuşlardır (Sorkun ve ark. 2002). Kutlu ve Bengü (2005) Gaziantep bölgesindeki bal örneklerinde diastaz sayısı ölçümleri sonucunda en düşük 2.5 en yüksek 38.5 ortalama 19.83 olarak değerlerini bulmuşlardır. Yapılan farklı çalışmalarda ise bal örneklerinin diyastaz sayılarının ortalamaları, 14.6 (Tolon 1999), 11.23 (Yılmaz ve Küfrevioğlu 2001), 17.97 (Velioglu ve Köse 1983), 29.40 (Şahinler ve Gül 2007) ve 20.19 (Gül 2008) olarak ölçmüşlerdir.

Çalışmamızda bütün bal numunelerinin diastaz sayıları hesaplanmış. En yüksek diastaz sayısı 17.90 ile BingölKarlıova, en düşük diastaz sayısı ise 1 ile Bingöl-Sancak Beldesi numunelerinde tespit edilmiştir. Bingöl-Sancak Beldesi ve Bingöl- Çaytepe köyü numuneleri hariç diğer tüm numunelerde diastaz sayısı 8'in üzerinde Türk Gıda Kodeksi Bal Tebliğine uygun çıkmıştır.

Bal içerisindeki karbonhidratların ısıtılması yada balların ıSı bakımından saklama ortamının uygun olmaması durumunda HMF isimli madde olușur. Bu madde insan sağlığı açısından zararlı bir maddedir. Balın uygunsuz bir şekilde depolanması ve uygulanan ısıl işlem, balın içerdiği şekerler ve aminoasitler arasındaki bağa bağlı olarak HMF bileşiğini oluşturmaktadır (Zappala ve ark. 2005). Türk Gida Kodeksi Bal Tebliğine göre balda yüksek $40 \mathrm{mg} / \mathrm{kg}$ HMF bulunabileceği öngörülmektedir (TGK 2012). Ölçülen değerin bu miktarın üzerinde çıkması balın uygun olmayan sıcak bir ortamda depolandığını ya da ısıl ișleme maruz kalmış olabileceğini göstermektedir ve bu özellikli balların satışı yasaktır (Zappala ve ark. 2005). Gaziantep bölgesi ballarında yapılan bir çalışmada HMF değeri en az 14.284 $\mathrm{mg} / \mathrm{kg}$, en yüksek $51.456 \mathrm{mg} / \mathrm{kg}$ ortalama $27.690 \mathrm{mg} / \mathrm{kg}$ olarak ölçmüşlerdir (Kutlu ve Bengü 2015). Batu ve arkadaşlarının (2013) yaptıkları çalışmada ölçümü yapılan ballardaki HMF değerleri 0,14 mg/kg ile $24.39 \mathrm{mg} / \mathrm{kg}$ arasında ortalama olarak $5.50 \mathrm{mg} / \mathrm{kg}$ olarak tespit etmişlerdir. Yapılan diğer araştırmalarda HMF içerikleri ortalama $3.3 \mathrm{mg} / \mathrm{kg}$ (Yılmaz ve Küfrevioğlu 2001), 7.84 mg/kg (Sorkun ve ark. 2002), 5.44 (Şahinler ve Gül 2004) ve $17.8 \mathrm{mg} / \mathrm{kg}$ (Terrab ve ark. 2002) olarak bildirilmiștir.

Çalıșmamızda ölçülen HMF değerlerinin en düşüğü 23.59 $\mathrm{mg} / \mathrm{kg}$ ile Binöl-Solhan numunesinde en yüksek değer ise $42.22 \mathrm{mg} / \mathrm{kg}$ olarak Bingöl-Yedisu numunesinde, ortalama olarak 32.14 mg/kg olarak ölçüldü. Ölçülen değerlerden sadece Bingöl-Çaytepe Köyü numunesi $42.22 \mathrm{mg} / \mathrm{kg}$ değeri ile Türk Gıda Kodeksi Bal Tebliğine uygun çıkmamış kalan numunelerin tümü $40 \mathrm{mg} / \mathrm{kg}$ altında olup $\mathrm{HMF}$ bakımından standartlara uygun çıkmıştır.

Türk Gıda Kodeksi Bal Tebliğine göre balda suda çözülmeyen madde miktarının en çok \%0.01 olabileceği söylenmiştir. Kutlu ve Bengü (2015) araştırmalarında Gaziantep bölgesindeki ballarda suda çözülmeyen madde miktarını \%0,002 ile \%0,093 aralığında ölçmüşler, ortalamasını ise \%0,027 olarak bildirmişlerdir. Başka bir araștırmada bal örneklerindeki suda çözülmeyen madde miktarı \%0,01ile \%0,09 arasında, ortalama \%0,03 olarak bildirilmiştir (Çetin ve ark. 2011). Çalışmada en düşük suda çözülmeyen madde miktarı \% 0.001 ile BingölMerkez, en yüksek değer \% 0.011 ile Bingöl-Sancak Beldesi bal örneklerinde ölçülmüștür. Ortalama suda çözülmeyen madde miktarı \% 0.00575 olarak hesaplanmıștır. Elde ettiğimiz tüm sonuçların Türk Gıda Kodeksi Bal Tebliğinin maksimum değerinin altında olduğu görülmüştür.

Bal içerisindeki kül içeriğindeki mineral maddelerden kaynaklanmaktadır. Külün miktarı ise arının kaynak olarak kullandığı bitkilere göre farklılık gösterir. Baldaki renk tonuyla içerdiği kül miktarı arasında bir bağlantı bulunmaktadır. Balın rengi koyulaştıkça içerdiği kül oranı da çoğunlukla artmaktadır (Thawley 1969). Batu ve arkadaşlarının (2013) yaptıkları çalışmada analizi yapılan ballarda kül oranının \%0.02 ile \%0.19 arasında değiștiği, ortalama $\% 0.07$ olduğu görülmüştür. Yapılan diğer araştırmalarda analizi yapılan ballarda kül oranları $\% 0.11$ (Gül 2008), \%0.13 (Şahinler ve Gül 2004) ve \%0,19 (Terrab ve ark. 2003) olarak bulunmuştur. Türk Gıda Kodeksi Bal Tebliği standartlarına göre çiçek ballarında olası kül miktarının \%0.6 değerinin altında olması gerekmektedir. Çalışmamızda ölçülen kül miktarlarının en düşüğü \% 0.39 ile Binöl-Genç numunesinde en yüksek değer ise \% 0.54 olarak Bingöl-Solhan numunesinde, ortalama olarak \% 0.45 olarak ölçüldü. Elde ettiğimiz sonuçlara göre bal numunelerinin tümü Türk Gıda Kodeksi Bal Tebliği standartlarına uymaktadır.

Sonuç olarak ölçülen parametrelere göre Bingöl ili ve ilçelerinden toplanan bal örneklerinin 3 bal örneği haricinde Türk Gıda Kodeksi Bal Tebliği standartlarına uyduğu görülmüştür. Bingöl coğrafi açıdan oldukça zengin bir bitki örtüsüne sahiptir. Bitki örtüsünün oluşumunda yılın büyük bir bölümünde güneşin fazla olmasının etkisi oldukça fazladır. Bölgede kışlar çok sert geçmektedir. Yazlarda kışların aksine oldukça sıcak geçmektedir. Bölgenin zengin bitki örtüsü arıcılık için çok uygundur. Üretilen balların kalitesi arıcılığın gelişimi ile artmaktadır. Ancak insanların kolay para kazanabilmek için balda sahtekârlıklar yapması bu kalitenin düşmesine sebep olmaktadır. Bunun engellenebilmesi için hem satıcıların hem de alıcıların konu hakkında bilinçlendirilmesi önemlidir.

\section{KAYNAKLAR}

Alqarni AS, Owayss AA, Mahmoud AA (2012). Mineral content and physical properties of local and imported honeys in Saudi Arabia. Journal of Saudi Chemical Society, 5, 618-625.

Artık N (2004). Bitkilerin bal potansiyeli ve balın bileșimi. Teknik Arıcılık Dergisi, 86, 21-24.

Batu A, Küçük E, Çimen M (2013). Doğu Anadolu ve Doğu Karadeniz Bölgeleri çiçek ballarının fizikokimyasal ve biyokimyasal değerlerinin belirlenmesi. Gıda Teknolojileri Elektronik Dergisi, 8(1), 52-62. 
Çetin K, Alkın E, Uçurum MHÖ (2011). Piyasada satılan çiçek ballarının kalite kriterlerinin belirlenmesi. Journal of Food and Feed ScienceTechnology, 11, 49-56.

Gül A (2008). Türkiye'de Üretilen Balların Yapısal Özelliklerinin Gıda Güvenliği Bakımından Araștırılması. Doktora tezi, Mustafa Kemal Üniversitesi, Fen Bilimleri Enstitüsü, Zootekni Anabilim Dalı, Hatay.

Karadal F, Yıldırım Y (2012). Balın kalite nitelikleri, beslenme ve sağlık açısından önemi. Erciyes Üniversitesi Veterinerlik Fakültesi Dergisi, 9(3), 197-209

Kutlu M, Bengü AŞ (2015). Gaziantep'te üretilen balların kalite kriterlerinin belirlenmesi, Tr. Doğa ve Fen Derg., 4(1), 48-53.

Ötleș S. (1995). Bal ve Bal Teknolojisi (Kimyası ve Analizleri). Alaşehir Meslek Yüksekokulu Yayınları, Manisa.

Paradkar MM, Irudayaraj J (2001). Discrimination and classification of beet and cane inverts in honey by FT-Raman spectroscopy. Food Chem., 76, 231-239.

Sorkun K, Doğan N, Gümüş Y, Ergün K, Bulakeri N, Işık N (2002). Türkiye'de üretilen doğal ve yapay balların ayırt edilmesinde fiziksel kimyasal ve mikroskobik analizleri. Mellifera, 2(4), 13-21.

Şahinler N, Gül A (2004). Yayla ve ayçiçeği ballarının biyokimyasal analizi. IV. Ulusal Zootekni Bilim Kongresi, 01-03 Eylül. Isparta.

Şahinler N, Gül A (2007). Isı Uygulaması ve Depolama Süresinin Cam Balının Kalitesi Üzerine Etkileri, 5. Ulusal Zootekni Bilim Kongresi, 5-8 Eylül. Van.

Sișek G, Sișek M, Arık M (2007). Arıcının El Kitabı, Doğu Anadolu Kalkınma Programı Tarım ve Kırsal Kalkınma Bileșeni Kaynarca Köyü Çiftçi Grubu Arıcılığı Geliştirme Projesi, Varto-Muş.
Terrab A, Diez MJ, Heredia FJ (2002). Characterization of Moroccan unifloral honeys by their physicochemical characteristics. Food Chemistry, 79, 373-379.

Terrab A, González G, Díez MJ, Heredia FJ (2003). Characterisation of Moroccan unifloral honeys using multivariate analysis. European Food Research and Technology, 218(1), 88-95.

Terrab A, Recamales AF, Hernanz D, Heredia FG (2004) Characterization of Spanish thyme honeys by their physicochemical characteristics and mineral contents. Food Chemistry, 88, 537-542.

TGK (2012). Türk Gıda Kodeksi Bal Tebliği (Tebliğ No: 2012/58) 27 Temmuz 2012 tarih ve 28366 sayll Resmî Gazete.

Thawley AR (1969). The components of honey and their effects on its properties, A Review. Bee World, 50(2), 51-60.

Tolon B, (1999). Muğla ve Yöresi Çam Ballarının Biyokimyasal Özellikleri Üzerine Bir Araştırma. Doktora Tezi, Ege Üniv. Fen Bil. Enst. İzmir.

Vanhanen LP, Emmertz A, Savage GP (2011). Mineral analysis of monofloral New Zealand honey. Food Chem, 128, 236-40.

Velioglu S, Köse G (1983). Ülkemizde üretilen ayçiçeği ballarının standarda (TS 3036) uygunluğu üzerinde bir araştırma. J. Nutr. and Diet., 17, 285293.

Yılmaz H, Küfrevioğlu İ (2001). Composition of honeys collected from eastern ant south-eastern anatolia and effect of storage on hydroxymethylfurfural content and diastase activity. Turkish Journal of Agriculture and Forestry, 25, 347- 349.

Zappala M, Fallico B, Arena E, Verzare A (2005). Methods for the determination of HMF in honey: a comparison. Food Control, 16(3), 273-277. 